\title{
MEDALLA HOMENAJE A MARCELINO MENÉNDEZ Y PELAYO POR SU ELECCIÓN COMO DIRECTOR DE LA REAL ACADEMIA DE LA HISTORIA, OBRA DE LORENZO COULLAUT VALERA
}

\author{
MEDAL HOMAGE TO MARCELINO MENENDEZ PELAYO \\ FOR YOUR CHOICE AS DIRECTOR OF \\ THE ROYAL ACADEMY OF HISTORY, WORK \\ LORENZO COULLAUT VALERA
}

\author{
Joaquín Manuel Álvarez Cruz \\ Universidad de Sevilla, Sevilla \\ jmac@us.es
}

\begin{abstract}
En este trabajo se estudia la medalla con la que Marcelino Menéndez y Pelayo fue homenajeado en 1910 con motivo de su elección como director de la Real Academia de la Historia. Magnífico ejemplo de la labor como medallista del escultor Lorenzo Coullaut Valera, en ella introduce múltiples rasgos de índole modernista que la dotan de gran interés y originalidad plástica.

Palabras clave: Escultura, medallística, Modernismo, Siglo XX, España, Andalucía, Lorenzo Coullaut Valera, Francisco de Goya, Marcelino Menéndez y Pelayo.
\end{abstract}

In this work there is studied the medal with which Marcelino Menéndez y Pelayo was honoured in 1910 on the occasion of his choice as the director of the Royal Academy of the History. Magnificent example of the labor as medalist of the sculptor Lorenzo Coullaut Valera, in her introduces multiple features of modernist nature that provide it with great interest and plastic originality.

Keywords: Sculpture, medals, Modernism, 20th century, Spain, Andalusia, Lorenzo Coullaut Valera, Francisco de Goya, Marcelino Menéndez y Pelayo.

El origen de las relaciones artísticas entre Lorenzo Coullaut Valera y Marcelino Menéndez y Pelayo hay que situarlo en el Madrid de finales del siglo XIX y más concretamente en el contexto de las tertulias que Juan Valera celebraba en su domicilio de la Cuesta de Santo Domingo, 3. Estas constituían el eje de la vida 
social del ilustre novelista egabrense, quien por causa de su ceguera había abandonado la carrera diplomática, tras pedir su jubilación en 1896, y prácticamente ya no salía de su casa. Tenían lugar todas las semanas, los sábados por la tarde, aunque desde 1897 pasaron a los domingos. A ellas asistían mayoritariamente literatos, aunque muchos de ellos también ocupaban importantes cargos en la Administración del Estado. Menudeaban los andaluces afincados en la Corte, como el doctor Thebussem (Mariano Pardo de Figueroa y de la Serna), Narciso Campillo y Correa, el conde de las Navas (Juan Gualberto López Valdemoro de Quesada), Blanca de los Ríos Nostench o los hermanos Álvarez Quintero; aunque no faltaban los de otras regiones, como Emilia Pardo Bazán, los Vázquez de Parga, Ramón Pérez de Ayala, Luis Vidart Schuch o Marcelino Menéndez y Pelayo ${ }^{1}$.

La presencia de Lorenzo Coullaut Valera en ella fue bastante frecuente a raíz de su traslado a Madrid. A ella llegó en 1897, tras el suicidio en 1896 de su primer maestro Antonio Susillo, buscando continuar su formación y abrirse camino en la escultura. Su condición de sobrino nieto del novelista le franqueaba las puertas de aquella casa, que no sólo visitaba como contertulio sino también como colaborador de su tío, a quien ayudaba en sus tareas literarias. Por aquellos años, dada su ceguera, Juan Valera tenía como secretario, lector y amanuense al joven egabrense Pedro de la Gala (por su juventud conocido familiarmente como Periquito de la Gala), pero en ocasiones, cuando éste no podía y ante su preocupación por concluir los trabajos que tenía comenzados y que por su edad y salud temía no poder terminar, su sobrino le leía algunos textos, en especial los escritos en francés. Al respecto cabría recordar que el joven escultor dominaba aquella lengua, tras haber vivido en Francia varios años, mientras cursaba en el Lycée Eugène Livet de Nantes los estudios preparatorios para el acceso a la carrera de ingeniero naval. Además su padre, Louis Alfred Coullaut Boudeville, natural de aquel país, desde pequeño le había familiarizado con aquel idioma por cuanto siempre pensó que su hijo mayor seguiría su carrera y que la estudiaría en el marco de las prestigiosas escuelas politécnicas francesas ${ }^{2}$.

De estos estrechos contactos se derivaron para el escultor benéficas consecuencias. En el plano humano, la admiración que por los clásicos sentía su tío dejó en su creatividad el amor por la belleza, la serenidad y el equilibrio. También aprendió de él a aproximarse a la Literatura con los ojos del crítico, es decir, a no

${ }^{1}$ BRAVO-VILLASANTE, Carmen: Biografía de don Juan Valera, Barcelona, Aedos, 1959, p. 229. CONTRERAS, Jesús C.: Valera D. Juan. Su perfil ignorado y algunas cartas inéditas, Madrid, Visión Net, 2005, pp. 115-116. RUBIO CREMADES, Enrique, "Biografía de Juan Valera", en Biblioteca Virtual Universal, http://www.biblioteca.org.ar/libros/132335.pdf [30/10/2013 11:14].

${ }^{2}$ CASCAleS MUÑOZ, José: Las Bellas Artes Plásticas en Sevilla. La pintura, la escultura y la cerámica artística desde el siglo XIII hasta nuestros días, Toledo, 1929, t. II, p. 66. CONTRERAS, Jesús C.: Valera D. Juan..., op. cit., p. 115. 
quedarse en la superficie de las palabras, sino a buscar su sentido oculto y descubrir sus recursos estilísticos. Asimismo, dejó en su temperamento una actitud vital moderada y tolerante.

En el terreno de las relaciones humanas, sus dotes personales, entre las que se contaban la simpatía y una buena cultura, junto a su condición de "sobrino", le permitieron forjar entre los allegados a Juan Valera, que quizá por ello nunca le consideraron un advenedizo, unos estrechos lazos de amistad que se mantendrían a lo largo de los años, y que dados los cargos de responsabilidad que muchos de ellos ocupaban o llegaron a ocupar en las instituciones culturales del Estado, le abrieron no pocas puertas y le brindaron numerosas oportunidades.

Como no podía ser menos, dada la amistad que le unía con Juan Valera, Menéndez y Pelayo también frecuentó aquella tertulia. Allí debieron presentarle al joven escultor, pero la diferencia de edad y sus muchas obligaciones por aquellos años - catedrático de Historia Crítica de la Literatura Española de la Universidad Central de Madrid, desde el 17 de diciembre de 1878, numerario de la Real Academia de la Lengua desde 1881, de la Real Academia de la Historia desde 1882, de la Academia de Ciencias Morales y Políticas desde 1889, de la Real Academia de Bellas Artes de San Fernando desde 1892 (aunque no tomó posesión hasta 1901), bibliotecario de la Academia de la Historia desde 1892, aunque desde tres años antes lo era interinamente, y director de la Biblioteca Nacional desde 1898- impidieron que la relación fuera más allá del mutuo, pero distante, conocimiento ${ }^{3}$.

No obstante, años después, en 1909, muerto ya Juan Valera, Lorenzo Coullaut Valera intentó retomar aquella relación con motivo del concurso de adjudicación del monumento a José María de Pereda en Santander, al que se había presentado junto a otros siete escultores. Convocado por el Ayuntamiento de esta ciudad, su jurado lo compusieron los miembros de la Comisión Provincial de Monumentos, bajo la presidencia de Marcelino Menéndez y Pelayo.

Sabiendo de los entresijos y apadrinamientos que rodeaban a los encargos artísticos oficiales y más o menos oficiales, Coullaut Valera, buscó allegarse algunas voluntades entre los componentes del jurado, al menos para equilibrar las que intentasen favorecer a alguno de sus competidores. Así, aprovechando la amistad que unía a su primo Luís Valera y Delavat (1870-1926), marqués de Villasinda, con Marcelino Menéndez y Pelayo, le pidió una recomendación para su trabajo. A tal fin, el segundo de los hijos varones de don Juan Valera -el primero, Carlos, falleció con 16 años- envió una carta a Menéndez y Pelayo en la que, con la excusa de preguntarle por la fecha exacta en la que finalizaba el plazo de presentación de los bocetos para el concurso del monumento a Pereda, le pedía que examinara y considerara particularmente el de su pariente, tanto por el afecto

3 “Menéndez y Pelayo, Marcelino", en Menéndez y Pelayo/ Vidal Biblioteca de Menéndez Pelayo, http://www.bibliotecademenendezpelayo.org/default.aspx?op=1\&htmlTarget=vida. htm [30/10/2014 11:19]. 
que le sentía como por su gran talento y delicado gusto, cualidades que venían confirmadas por la opinión de Jacinto Octavio Picón y de otros críticos de arte 4 .

El efecto de esta carta de recomendación fue poner en un compromiso a Menéndez y Pelayo, quien antes de nada quiso conocer directamente al tan encomiado artista. Visitó su estudio y pudo contemplar los trabajos preparatorios del proyecto que iba a enviar al concurso. La gentileza del escultor y la calidad de los bocetos le agradaron, de modo que le dio una tarjeta de presentación para su hermano Enrique, miembro de la Comisión de Monumentos de Santander y en consecuencia vocal del jurado ${ }^{5}$.

Desconocemos el contenido de esta tarjeta, no obstante, don Marcelino era una persona que por su moral y formación intelectual estaba muy lejos de corruptelas y estratagemas, de modo que resulta plausible suponer que en ella no fue más allá de una amable presentación. Pero para confirmar esta suposición contamos con las epístolas que por esas fechas y en relación a este tema se intercambiaron el ilustre polígrafo y su hermano Enrique Menéndez y Pelayo.

A través de la carta que Marcelino Menéndez y Pelayo escribió a su hermano Enrique el 24 de febrero de 1909, podemos conocer de manera personal e íntima la verdadera actitud que aquél mantuvo para con Coullaut después de la mencionada visita a su estudio. En ella informa a su hermano de la visita que próximamente le haría el escultor y de la tarjeta que de su parte le entregaría, pero también le hace algunos comentarios en torno a su persona y su obra, que muestran su exacta disposición hacia él. Así, lo describe como a un "mozo de mucho provecho" y "verdadero artista", le comenta que vio el proyecto monumental en su taller y le manifiesta sus dudas de que se presente algo mejor, aunque matiza diciéndole: "en la ejecución hay de todo, lo que menos me gusta, porque tiene poco carácter, es la figura, pero ya se sabe que en estos monumentos que ahora se estilan, la estatua del personaje se sacrifica al conjunto. Los bajorrelieves tomados de las obras de Pereda me parecen de gran mérito". Finalmente le justifica su interés por él en base a su parentesco con don Juan Valera, pero se lamenta de que Aniceto Marinas no ultimase su proyecto y le pide que le envíe sus impresiones y fotografías de todas las obras presentadas "para votar en conciencia"6.

${ }^{4}$ Archivo de la Biblioteca Menéndez y Pelayo, Santander, Epistolario de D. Marcelino Menéndez y Pelayo, Carta de D. Luis Valera a D. Marcelino Menéndez y Pelayo, s/f. "Muerte del marqués de Villasinda", en $A B C$, Madrid, 2-VII-1926, pág. 10. "Luis Valera Delavat", en GeneaNet, http://gw.geneanet.org/sanchiz?lang=es\&p=luis\&n=valera+delavat [30/09/2014 11:22]. "Luis Valera Delavat", en GeneallNet, http://www.geneall.net/H/per_ page.php?id=618665 [30/09/2014 11:24].

${ }^{5}$ SÁNCHEZ REYES, Enrique, Epistolario de Enrique y Marcelino Menéndez y Pelayo, Santander, Sociedad de Menéndez Pelayo, 1954, pp. 167-168.

${ }^{6}$ Ibídem. 
El mismo tono de ecuanimidad se mantiene en la respuesta que a esta misiva dio Enrique Menéndez y Pelayo el dos de marzo de 1909. En ella informa a su hermano que Coullaut Valera ya le había visitado y que le había parecido "un hombre bien simpático y atractivo". En relación con su proyecto le dice que comparte su parecer con respecto a la bondad de los relieves y le comenta que parece el mejor de los presentados, pues según advierte: "es el que muestra más sentimiento del escritor y de sus obras". Sin embargo, el tema central de la misiva no fue el escultor y su proyecto, sino las dificultades que tenía don Marcelino para abandonar su puesto en la dirección de la Biblioteca Nacional y trasladarse a Santander para asistir a las deliberaciones del jurado en el que figuraba como presidente ${ }^{7}$.

La noticia de estas dificultades llegó hasta los escultores participantes en el concurso, quienes no vieron de buen grado la ausencia de Menéndez y Pelayo, pues su presencia en Santander les daba la garantía de que aquél se resolvería con ecuanimidad. Uno de ellos, Julio González Pola, le envió una carta al polígrafo preguntándole claramente al respecto, ya que si su comparecencia no se producía estaba decidido a retirar su proyecto antes de que el jurado emitiese su fallo ${ }^{8}$. La idea de impugnar el veredicto si no era emitido de conformidad con las bases de la convocatoria comenzó a arraigar entre los concursantes, quienes en conversaciones informales se la hicieron llegar a algunos de los miembros del jurado 9 . El tema estaba en el ambiente y se planteó en la primera de las reuniones celebrada por éste, que tuvo lugar el primero de marzo de 1909. Asistieron a ella sus vocales, los miembros de la Comisión Provincial de Monumentos, y actuó de presidente, en ausencia de Marcelino Menéndez y Pelayo, el gobernador civil, el Sr. Bernard. Sin embargo, no se tomó ninguna resolución debido al problema de procedimiento que había planteado. Decidieron, en consecuencia, consultar al alcalde, como presidente de la junta ejecutiva del monumento, si ésta estaba conforme con que el fallo se emitiese sin la presencia de Marcelino Menéndez y Pelayo, por lo que a la espera de la respuesta se cerró la sesión ${ }^{10}$.

Ante la magnitud que estaba tomando el asunto y en previsión de un posible enfrentamiento entre concursantes y jurado, cuyo resultado era imprevisible y podía ser negativo para sus intereses, tres de los escultores participantes, Aurelio Carretero, González Pola y Coullaut Valera, se entrevistaron el dos de marzo con el alcalde de Santander y le informaron de que ellos estaban dispuestos a acatar el veredicto del jurado aunque no estuviese presente Marcelino Menéndez y Pelayo $^{11}$.

\footnotetext{
${ }^{7}$ Ibíd., pp. 168-169.

${ }^{8}$ Ibíd., pp. 167-170.

${ }_{9}$ Ibid., pp. 168-169.

10 "El monumento a Pereda", en El Diario Montañés, Santander, 2-III-1909, p. 1.

11 "El monumento a Pereda", en El Diario Montañés, Santander, 4-III-1909, p. 1.
} 
El papel jugado por Coullaut Valera, hombre diplomático y conciliador, en la resolución del problema debió ser clave, más aún cuando en su caso particular la apertura de una nueva convocatoria, en la que los contrincantes tal vez no fuesen tan de segunda fila y entre los que no estaría tan bien colocado como en aquellos momentos, le podía resultar especialmente perjudicial. También hay que señalar como la actuación concertadora de Coullaut sacó a Menéndez y Pelayo de la difícil situación en la que le habían colocado. Aunque carecemos de prueba alguna donde se demuestre que la acción del escultor tuvo este sentido, sí sabemos que estaba al tanto de las preocupaciones que el tema del concurso estaba causando al polígrafo. Muestra de ello fue la visita que hizo a su hermano, Enrique Menéndez y Pelayo, en la mañana del día tres de marzo, horas antes de partir hacia Madrid, para informarle del positivo resultado de la reunión que, junto a Aurelio Carretero y González Pola, había mantenido con el alcalde ${ }^{12}$.

De inmediato, en carta fechada ese mismo día tres de marzo de 1909, Enrique Menéndez y Pelayo comunicó a su hermano los detalles de la reunión que Coullaut Valera y los escultores díscolos habían tenido con el alcalde, y aprovechó la misiva para darle sus impresiones sobre el desarrollo del concurso monumental: "Por aquí la opinión de las gentes ajenas al jurado ha dado su preferencia, puede decirse que por unanimidad, al de Coullaut Valera. Y te advierto que los ha visto medio Santander, pues se deja entrar a todo el mundo a ver los bocetos, que son ocho, aunque la deliberación no creo que pueda hacerse sino sobre cuatro de ellos a lo más. A mí también es el que más me gusta el de Valera"13.

Resuelta la cuestión de procedimiento, el cinco de marzo de 1909, el jurado volvió a reunirse para emitir su fallo. Ante la imposibilidad de asistir por parte de Marcelino Menéndez y Pelayo, se nombró para ocupar su lugar en la presidencia del mismo a Justino Bernard, gobernador civil de la provincia. Tras minucioso estudio y largo debate se procedió a la votación, cuyo resultado fue el siguiente: el proyecto del escultor Carretero, cuatro votos, y el proyecto del escultor Coullaut Valera, cuatro votos. Ante el empate, el presidente, Justino Bernard, hubo de ejercer su voto de calidad y se lo dio al escultor Coullaut Valera. A continuación, tras estudio, se admitió el voto por escrito del vocal Máximo Solano, que fue favorable al proyecto de Coullaut Valera ${ }^{14}$. Por último se acordó enviar una copia del acta del fallo del jurado, las memorias de los proyectos y las fotografías de los bocetos a Marcelino Menéndez y Pelayo para que emitiese su voto ${ }^{15}$. Finalmente, unas dos semanas más tarde, también se recibió el voto de Marcelino Menéndez y Pelayo, que recayó en favor de Coullaut Valera, con lo que quedó definitivamente

\footnotetext{
${ }^{12}$ SÁNCHEZ REYES, Enrique, Epistolario..., op. cit., pp. 170-171.

${ }^{13}$ Ibídem.

14 "El monumento a Pereda", en El Diario Montañés, Santander, 8-III-1909, p. 1.

15 "El monumento a Pereda", en El Diario Montañés, Santander, 6-III-1909, p. 1.
} 
cerrada la cuestión de la adjudicación del monumento santanderino a José María de Pereda ${ }^{16}$.

Tras firmar el pertinente contrato con el Ayuntamiento santanderino - el 16 de abril de 1909-, Lorenzo Coullaut Valera se puso a la labor con la pretensión de tener terminado el conjunto monumental lo antes posible. Sin embargo surgieron algunos problemas en relación con la concesión por parte del Estado del bronce necesario para fundir la estatua de Pereda. En solicitud de ayuda para acelerar los trámites, escribió al alcalde de la capital cántabra y a Enrique Menéndez y Pelayo. En la carta dirigida a este último, le solicitaba que rogase a su hermano para que intercediera ante Antonio Maura, presidente del Consejo de Ministros en aquellos momentos, para que el Gobierno, a través de las Cortes, otorgara el citado bronce ${ }^{17}$. Desconocemos las gestiones que don Marcelino en su condición de senador pudo llevar a cabo, pero lo cierto es que la cuestión se resolvió y el monumento a Pereda fue solemnemente inaugurado el 23 de enero de $1911^{18}$.

Los siguientes contactos entre Lorenzo Coullaut Valera y Marcelino Menéndez y Pelayo, aunque artísticos e indirectos, no tardaron en producirse y tuvieron lugar en 1910, con motivo de la realización de la medalla con la que sus amigos le homenajearon por su elección como director de la Real Academia de la Historia.

La riqueza y amplitud de la labor intelectual de Menéndez Pelayo, le llevaron a ser elegido miembro de las principales academias que en el ámbito de las Artes y Humanidades existían en España. Como señalamos, fue numerario de la Real Academia Española, de la Real Academia de la Historia, de la Real Academia de Ciencias Morales y Políticas y de la Real Academia de Bellas Artes de San Fernando. Sin embargo, las envidias y la politización de estas instituciones, donde desde la elección de sus individuos hasta el nombramiento de sus cargos directivos estaba al servicio de intereses personales y extraacadémicos, hicieron que su paso por alguna de ellas le deparara importantes sinsabores.

Estos se iniciaron en 1902, cuando quiso ser director de la Academia de San Fernando, y no lo consiguió; pero alcanzaron su grado máximo en 1906, cuando pretendió ser elegido presidente de la Real Academia Española. Propuesto por Benito Pérez Galdós y Jacinto Octavio Picón, contó con los apoyos de ínclitas personalidades de la vida cultural española, entre otros, de Nicolás Salmerón, Pío Baroja, Felipe Trigo y Manuel Azaña, los hermanos Álvarez Quintero, Gregorio Martínez Sierra, Carlos Arniches, Joaquín Dicenta, Azorín, Antonio Machado, Álvaro de Albornoz, Pedro Mata, Augusto Barcia, Ramón Pérez de

16 "El monumento a Pereda", en El Diario Montañés, Santander, 8-VII-1909, p. 1. SÁNCHEZ REYES, Enrique, Epistolario..., op. cit., pp. 171-172.

${ }^{17}$ SÁNCHEZ REYES, Enrique, Epistolario..., op. cit., pp. 180-181.

18 ÁLVAREZ CRUZ, Joaquín Manuel, "El monumento a José María de Pereda en Santander", en Altamira, n ${ }^{\circ}$ LVIII, vol. II, Santander, segundo semestre del 2001. pp. 253292. 
Ayala, Eduardo Zamacois, Francisco Villaespesa y Gabriel Miró, quienes pidieron a su contrincante y amigo, además de compañero en el Partido Conservador, Alejandro Pidal, que retirara su candidatura. Sin embargo, éste no lo hizo, y en la votación celebrada en la noche del 22 de noviembre de 1906, consiguió 16 votos, mientras que Menéndez Pelayo tan sólo recibió tres, los de Jacinto Octavio Picón, José Ortega y Munilla y Juan Cavestany. Se vio, así, traicionado por su antiguo amigo, a quien él mismo había propuesto como miembro de aquella institución en 1882, y menospreciado por sus compañeros en la Academia. Señalemos que al año siguiente, el 5 de diciembre de 1907, cuando se volvió a repetir la votación, por cuanto Pidal y Mon había ocupado el cargo interinamente, los resultados fueron muy parecidos. Pidal recibió 11 votos y únicamente siete apoyaron a Menéndez y Pelayo: Pérez Galdós, que no pudo asistir a la anterior votación, Echegaray, que no pudo votar en la ocasión precedente, el padre Miguel Mir, que retiró su voto a Pidal, Picón, Ortega Munilla, Francisco Rodríguez Marín, recién llegado a la Academia, y Eduardo Saavedra ${ }^{19}$.

Afortunadamente, cuando optó a la dirección de la Real Academia de la Historia, la cuestión fue muy diferente gracias al caballeroso comportamiento de sus compañeros en la misma. La muerte del marqués de la Vega Armijo, el 12 de junio de 1908, antes de cumplir su trienal mandato, determinó la convocatoria de elecciones para nombrar un nuevo director que ocuparía el puesto interinamente hasta la fecha de celebración los comicios para el siguiente trienio. Se presentaron dos candidatos, Menéndez y Pelayo y Eduardo Saavedra, pero después de dos votaciones ninguno obtuvo la mayoría. En esta tesitura, dado que su contrincante era ya anciano y algo achacoso, y que, como señalamos, le había apoyado en las segundas votaciones a la dirección de la Academia de la Lengua, Menéndez y Pelayo decidió retirarse y no disputarle el cargo. Cuando al año siguiente, cumplido el trienio, se abrió el reglamentario periodo electoral, Eduardo Saavedra le devolvió el gesto y no se presentó, dejando el camino expedito a Menéndez y Pelayo, quien en las elecciones del 19 de noviembre de 1909 fue elegido nuevo director, por mayoría a excepción de un voto ${ }^{20}$.

19 "La Academia de la Lengua", en $A B C$, Madrid, 23-XI-1906, pp. 5-6. PALOMERO, Antonio, "Un hecho muy desagradable", en $A B C$, Madrid, 23-XI-1906, p. 6. "Notas de la tarde", en $A B C$, Madrid, 6-XII-1907, p. 2. SÁNCHEZ REYES, Enrique, Biografía Crítica y Documental de Menéndez y Pelayo. Barcelona, Aedos, 1956, págs. 285-91. "Marcelino Menéndez Pelayo", Biblioteca Virtual Miguel de Cervantes, http://bib.cervantesvirtual. com/bib_Autor/mmenendezpelayo/pcuartonivel.jsp?conten=autor\#6 [01/10/2014 19:30].

20 "En la Academia de la Historia", en La Época, Madrid, 17-XII-1909, pág.2. "Academia de la Historia", en El Globo, Madrid, 18-XII-1909, p. 1. "Academia de la Historia", en La Vanguardia, Barcelona, 18-XII-1909, p. 10. SÁNCHEZ REYES, Enrique, Biografía Crítica..., op. cit., pp. 291-292. 
Aquel triunfo dio pie a que un grupo de admiradores, discípulos y compañeros acordaran desagraviarle de los disgustos pasados, rindiéndole un homenaje conmemorativo y solidario a su elección como director de la Real Academia de la Historia cuyo eje sería la acuñación de una medalla que recordase para las generaciones venideras aquel feliz acontecimiento. Para el mejor logro del proyecto, el 2 de marzo de 1910 constituyeron una comisión, cuyos miembros fueron Adolfo Bonilla y San Martín, Juan Catalina García, Eduardo de Hinojosa, José R. Mélida, Juan Menéndez Pidal, Ramón Menéndez Pidal, Jacinto Octavio Picón, Francisco Rodríguez Marín y Rafael de Ureña y Smenjaud ${ }^{21}$.

Con el fin de darle mayor difusión a la idea, sus promotores publicaron una circular donde apelaban a los amantes de la cultura nacional para que sin distinción de doctrinas ni escuelas, y unidos por el amor a España y a la Literatura, se sumaran a este homenaje al autor de La Historia de las Ideas Estéticas.

Desconocemos los términos en los que Lorenzo Coullaut Valera se hizo cargo de la realización de la medalla, aunque sabiendo que varios de los miembros de la comisión ejecutiva del homenaje se contaban entre sus amigos, que su tío Juan Valera y Menéndez y Pelayo tuvieron una estrecha amistad y que el mismo había mantenido algunos y cordiales contactos personales con el egregio cántabro, es casi seguro que se ofreciera generosamente para realizar su modelo ${ }^{22}$.

Los participantes en el homenaje se suscribían al mismo con la compra de una papeleta que, por importe de diez pesetas, daba derecho a una medalla en bronce. La lista de adhesiones quedó abierta en la administración de la Revista de Archivos, Bibliotecas y Museos, y en muy poco tiempo, pues se cerró el primero de mayo de 1910, se sumaron a ella 700 admiradores del maestro, lo que fue todo un éxito. No obstante, y a pesar de la diligencia con la que se estaba llevando el asunto, retrasos en el trabajo de Coullaut y en el proceso de acuñación impidieron que el homenaje pudiera realizarse aquella misma primavera, por lo que se hubo de retrasar hasta pasado el verano ${ }^{23}$.

Señalemos que de la acuñación se encargo el escultor Carlos Palao Ortubia (1857-1934), miembro de una dinastía de artistas zaragozanos, procedentes de Murcia, en la que también destacaron su padre, el escultor Antonio José Palaos Marco (1824-1886), y su hermano, el pintor Luis Palao Ortubia (1863-?). Tras estudiar en la Escuela de Bellas Artes de Zaragoza y posteriormente en la de Madrid, Carlos Palao completó su formación en París y Roma. A su vuelta, se instaló en Zaragoza, donde se hizo cargo del taller familiar. Fue profesor de Dibujo del Antiguo en la Escuela de Artes Industriales local, conservador, entre

${ }^{21}$ Medalla en Honor de Menéndez y Pelayo, Madrid, Tip. de la Revista de Arch. Bibl. y Museos, 1910, p. 5.

22 "Academias y centros", en $A B C$, Madrid, 9-III-1910, p. 8.

${ }^{23}$ Medalla en Honor de Menéndez..., op. cit., p. 4. SÁNCHEZ REYES, Enrique, Biografía Crítica..., op. cit., pp. 292-293. 
1888 y 1914, del Museo Provincial de Bellas Artes y director del mismo desde 1916. Entre sus obras merecen mención, las alegorías de la Pintura, la Escultura y la Arquitectura, para la fachada del Museo de Zaragoza. Fueron también destacables sus tareas de restauración, como las que llevó a cabo en la portada renacentista de la iglesia de Santa Engracia, en Zaragoza ${ }^{24}$.

Terminadas las labores de acuñación, el 25 de octubre de 1910 pudo al fin llevarse a cabo el añorado homenaje. Tuvo lugar en el despacho de la dirección de la Biblioteca Nacional y fue un acto muy sencillo, durante el que los señores Bonilla San Martín, Ureña, Hinojosa, Picón, Rodríguez Marín, Catalina, García y los hermanos Menéndez Pidal, miembros todos de la comisión organizadora, hicieron entrega a Menéndez y Pelayo de una de las cuatro acuñaciones en oro que se habían hecho de la medalla. Éste agradeció aquella manifestación de aprecio con la lectura de unas cuartillas en las que recordando el homenaje que se le hizo cuando fue nombrado director de la Biblioteca Nacional, señaló que sólo aceptaba este nuevo agasajo en su condición de "obrero firme y constante de la Historia Intelectual de España”. Tras referir entre otros aspectos que el eje de su pensamiento había sido la comprensión "del genio nacional y de los inmortales destinos de España”, concluyó con la reflexión: “...ningún pueblo se salva y emancipa sino por su propio esfuerzo intelectual, y éste no se concibe sin la propia conciencia de sí mismo, que sólo puede formarse con el estudio recto y severo de la Historia" ${ }^{25}$.

De esta medalla, además de las acuñadas en bronce, se hicieron cuatro ejemplares en oro, que fueron entregados a Marcelino Menéndez y Pelayo, a S. M. Don Alfonso XIII y al Ayuntamiento de Santander, siendo el cuarto adquirido por el conde de la Viñaza con destino a la Real Academia de la Historia ${ }^{26}$.

La satisfacción que Coullaut Valera tuvo con este trabajo hizo que lo presentara a la Exposición Nacional de Bellas Artes de 1910, que en aquella edición tuvo lugar en el mes de octubre y no en el de mayo como era usual ${ }^{27}$.

La medalla, de 59'51 milímetros de diámetro y 55'4 gramos de peso (versión de bronce), muestra en su anverso el retrato de Menéndez y Pelayo y en su reverso

24 "Palao, los", en Gran Enciclopedia Aragonesa, http://www.enciclopedia-aragonesa. com/voz.asp?voz_id=9799 [02/10/2014 14:15].

${ }^{25}$ Medalla en Honor de Menéndez..., op. cit., pp. 15-16. "En honor de Menéndez y Pelayo", en $A B C$, Madrid, 26-X-1910, pp. 10-11.

${ }^{26}$ SÁNCHEZ REYES, E, Biografía Crítica..., op. cit., pp. 292-93. ALMAGRO CORREA, Martín, "Entrega a Marcelino Menéndez y Pelayo de la medalla en su honor en el Palacio de Bibliotecas y Museos, por haber sido elegido director de la Real Academia de la Historia", en ANES Y ÁLVAREZ DE CASTRILlÓN, Gonzalo, Don Marcelino Menéndez Pelayo en la Real Academia de la Historia, Madrid, Real Academia de la Historia, 2006, p. 100.

${ }^{27}$ Catálogo Oficial de la Exposición Nacional de Pintura, Escultura y Arquitectura de 1910, Madrid, Mateu, 1910, p. 66. 
una alegoría de la Historia ${ }^{28}$. Comenzando por el primero, digamos que su tipo presenta la efigie de Menéndez y Pelayo de medio cuerpo, en tres cuartos, rodeado de libros. Lo capta mientras escribe en su mesa de despacho, pero mirando al espectador. A modo de leyenda, en el borde superior derecho, puede leerse en letras excisas "A MENENDEZ Y PELAYO", y en el lateral izquierdo, ante su rostro y en 11 líneas con letras excisas de diferente tamaño, la inscripción "ELECTO/ DIRECTOR/ DE LA/ REAL/ ACADEMIA/ DE LA/ HISTORIA/ SUS/ ADMIRADORES/ MADRID/ 1910". En el reverso la alegoría de la Historia la componen tres figuras. En el centro de la composición aparece la Historia, sentada sobre una roca, ataviada con livianos velos y peinada con un recogido suelto de recuerdo clásico. Aunque escribe sobre un gran libro que apoya en sus rodillas, se gira hacia su espalda por donde aparece la figura del Tiempo. La encarna un fornido anciano alado de luengas barbas, que sostiene en su mano izquierda, junto a su pecho un pesado reloj de arena, mientras que en la mano derecha porta una guadaña. Tras la Historia se sitúa la Verdad, en pie, vestida con chitón e himatión tan clásicos como su peinado. Apoya la mano derecha sobre el alto montón de libros que aquélla lleva escritos y también se gira hacia el Tiempo, al que ilumina con la lucerna que sostiene en alto con su mano izquierda. La firma del escultor "LORENZO/ COVLLAVT/ VALERA", aparece en letras incisas a la izquierda de la roca sobre la que se sienta la Historia.

Desde un punto de vista iconográfico el anverso de la medalla muestra en tres cuartos el retrato de Menéndez y Pelayo, resuelto con un planteamiento muy naturalista y ajustado a su apariencia física por aquellos años. A tal fin, Coullaut Valera se sirve de retratos fotográficos contemporáneos, en especial de uno realizado por Antonio Cánovas del Castillo y Vallejo, de pseudónimo Dalton Kaulak o simplemente Kaulak, que mostramos en el apartado gráfico de este estudio y que que poco tiempo después apareció publicado en la prensa gráfica madrileña con motivo de la muerte del polígrafo ${ }^{29}$. En el mismo y como era usual en la iconografía del santanderino, éste dirige su mirada al espectador y establece un diálogo visual con él. Esta peculiaridad en la imagen pública de Menéndez y Pelayo, ya la recoge Joaquín Sorolla en el retrato que le hizo en 1908 para la Hispanic Society de New York, al igual que José Moreno Carbonero en el que le pintó poco después, en 1912, para la Real Academia de la Historia. Si bien esta actitud en

${ }^{28}$ Los ejemplares que se conservan en la Real Academia de la Historia en versiones de oro y bronce ( $\mathrm{n}^{\circ}$ inv. RAH $\mathrm{n}^{\circ}$ II.3.1. 763 y 764) dan un peso de 77,98 gramos y un diámetro, módulo, de 60 milímetros, Vid. ALMAGRO CORREA, Martín, "Medalla de Homenaje a Marcelino Menéndez y Pelayo como director de la Real Academia de la Historia (1910)", en ANES ÁLVAREZ DE CASTRILLÓN, Gonzalo (coord.), Don Marcelino Menéndez Pelayo..., op. cit., p. 97.

29 "Muerte de Menéndez Pelayo", en Mundo Gráfico, año II, no 30, Madrid, 22-V1912, p. 17. 
el ámbito del retrato pictórico era lo más usual, en el caso de las medallas resultaba una novedad. Lo más frecuente en ellas desde sus ejemplos grecorromanos, era que el efigiado apareciera de perfil, rasgo que se mantuvo como estereotipo hasta el Romanticismo cuando escultores como David D'Angers trabajaron la medallística. Con un concepto escultórico no exento de acentos pictóricos, comenzaron a introducir retratos en tres cuartos e incluso frontales. Sin embargo, en ellos muy rara vez el personaje mira al espectador y ésta es otra novedad iconográfica que Coullaut introduce en esta medalla y en el género. También resulta inusual, aunque sea heredero de soluciones decimonónicas, el que en esta medalla el retrato del personaje se prolongue, no sólo más allá del cue1lo, sino que incluya parte del torso y muestre los brazos y manos, en esta ocasión, en actitud de escribir sobre una mesa donde aparecen útiles de escritura e incluso libros, elementos que actúan como atributos parlantes y nos hablan de la condición de asiduo lector y escritor del ilustre cántabro. Completan la iconografía del anverso una leyenda, detrás del personaje, que lo identifica, y una inscripción, ante él, que explica el homenaje motivo de la acuñación. El reverso, por su parte, desarrolla una alegoría de la Historia, para cuya formulación Coullaut Valera partió de La Verdad, el Tiempo y la Historia, un lienzo pintado por Goya entre 1802 y 1805 , que se supone formaba parte de un grupo de ocho alegorías destinadas a decorar dos salas públicas de la residencia gubernamental de Manuel Godoy, más específicamente de las cuatro en formato rectangular destinadas a la antesala de su despacho. Éstas desaparecieron de aquel palacio entre 1808 y 1813, durante la Guerra de la Independencia. No obstante, tanto la que nos ocupa como una de sus compañera, la alegoría de La Poesía, llegaron en 1961, tras muchas vicisitudes, al Museo Nacional de Estocolmo, donde se conservan ${ }^{30}$.

En concreto, La Verdad, el Tiempo y la Historia era una alegoría sobre la verdad histórica y el papel imprescindible que en ella tiene el tiempo ${ }^{31}$. Muestra en su centro a la Historia, sentada de perfil sobre una sólida roca y semidesnuda, escribiendo afanosamente en un libro, mientras pisa otros situados a sus pies y que

${ }^{30}$ ROSE DE VIEJO, Isadora, "Daños colaterales: la dispersión y destrucción de los cuadros de Goya pintados para Godoy", en CABAÑAS BRAVO, Miguel, LÓPEZYARTO ELIZALDE, Amelia y RINCÓN GARCÍA, Wifredo (coords.), Arte en tiempos de guerra, Madrid, CSIC, 2009, pp. 441-443.

${ }^{31}$ GLENDINNING, Nigel, Francisco de Goya, Madrid, Historia 16, 1993, pp. 80-84. GLENDINNING, Nigel, "La alegoría de Goya relacionada con la Historia y la Poesía", en I Congreso Internacional. Pintura Española. Siglo XVIII, Marbella, Museo del Grabado Español Contemporáneo, 1998, p. 461-472. ROSE DE VIEJO, Isadora, "Daños colaterales..., op. cit., pp. 441-443. ROSE-DE VIEJO, Isadora, "Las alegorías de Goya para el palacio madrileño de Godoy", en VV. AA., Goya, Madrid, Fundación Amigos del Museo del Prado y Barcelona, Galaxia Gutenberg-Círculo de Lectores, 2001, pp. 99-118. REYERO, Carlos, Alegoría, Nación y Libertad: El Olimpo constitucional de 1812, Madrid, Siglo XXI, 2010, pp. 82-83. 
aún están abiertos. Tras ella aparecen el Tiempo y la Verdad. El primero es representado por un anciano alado que sostiene un reloj de arena en su mano izquierda mientras con la derecha coge del brazo a la Verdad, simbolizada por una joven vestida de blanco que lleva en su mano derecha un libro y porta en su izquierda un cetro. Si bien esta lectura iconográfica vendría avalada por el boceto titulado El Tiempo, la Verdad y la Historia, que se conserva en el Museo de Boston y que fue pintado por Goya entre 1797 y 1799, otros estudios iconográficos han variado esta interpretación. Según ellos, cuando Goya convierte el referido boceto en obra definitiva la figura de la Verdad rescatada de la oscuridad por el Tiempo, se transmuta en la Filosofía, según advierte la fidelidad con la que sigue el modelo que de ella da Cesare Ripa en su Iconología y muy especialmente la estampa que lo desarrolla en la edición romana de $1603^{32}$. Este cambio se explica en un contexto de madurez artística y personal de Goya. De un lado, prefiere no ser redundante, ya que la figura de la Historia, al presentarse desnuda ya señalaba su compromiso con la verdad; y de otro desea mostrar su compromiso con los ideales ilustrados así como el de su mecenas Manuel Godoy, quien con este encargo destinado a la antesala de su despacho oficial, quería manifestar, para quienes supieran verlo, su compromiso con aquel ideario y con el progreso científico y económico que conllevaba. De este modo Goya quiere presentar a la Historia como una ciencia moderna. Así, no la respalda sobre un fondo tenebroso poblado de seres diabólicos, como en el boceto de Boston, sino que la ambienta en un paisaje natural luminoso y atractivo, donde el elemento más sobresaliente es el gran árbol que lo recorre en diagonal y que busca testimoniar el momento histórico de libertades que se estaba iniciando para Europa. En ese ámbito, en primer término, en el centro, se coloca la Historia, sentada de perfil sobre una sólida roca, mirando hacia atrás -al pasado- y escribiendo en el libro que apoya sobre su regazo. Aparece semidesnuda, cubriendo sólo sus piernas con unos paños amarillo-verdosos. El amarillo, como su desnudez, alude a su compromiso con la verdad, aunque el verde indica que ésta no es inamovible sino que está viva y por tanto en proceso de constante renovación. Ello enlaza con los libros que tiene ante sí y está pisando. Los acaba de escribir, pero siguen abiertos para poder ser enmendados al hilo de nuevos descubrimientos. De este momento se alude a que la Historia no sólo busca la verdad sino también su permanente actualización. Tras la Historia aparecen el Tiempo y la Filosofía, como surgiendo de aquel espacio de libertades que caracterizaba el árbol inclinado. El Tiempo, el inseparable acompañante de la Historia, es representado por un anciano con barbas, signo del paso del tiempo, al igual que sus alas, en alusión al proverbio latino Volat irreparabile tempus (el tiempo vuela irremediablemente). En su mano izquierda porta un reloj de arena con la ampolla superior llena, para situarnos al comienzo una nueva era. Ella es la que posibilita

${ }^{32}$ RIPA, Cesare, Iconologia overo Descrittione di diverse Imagini cavate dall'antichità et di propria inventione, Roma, 1603, pp. 164-165. 
que traiga de la mano a la Filosofía, la que será nueva compañera de la Historia en busca de orientar y organizar su saber desde principios racionales. La caracteriza, como dijimos, siguiendo las sugerencias de Ripa, aunque depurándolas y actualizándolas, de tal modo que la muestra como una mujer de gran dignidad, según advierten sus aristocráticos y blancos ropajes, por cierto muy a la moda del momento, mirando al frente que no al cielo, con un libro cerrado en su mano derecha, compendio los tres que llevaba en la estampa de Rippa y que simbolizaban a las tres disciplinas filosóficas, y sosteniendo un cetro en su izquierda, distintivo de su dominio sobre todas las ciencias humanas ${ }^{33}$. De todas formas, otras interpretaciones prefieren titular este cuadro como España, el Tiempo y la Historia o Alegoría de la adopción de la Constitución de 1812, en base a considerar que la figura que trae del brazo el Tiempo no es la Filosofía, sino la nueva España nacida de la Constitución de 1812, tal y como señalan el que porte su texto en la mano derecha y en su izquierda sostenga el cetro real, indicando así la primacía del poder constitucional sobre el monárquico y el fin del Antiguo Régimen. Mientras, la Historia se limita a tomar nota de aquellos acontecimientos, a la vez que pisa los antiguos textos legales ${ }^{34}$.

Ignoramos como Coullaut Valera llegó a conocer este cuadro, pero hacia 1910 se encontraba en Madrid. Tras las rapiñas de la Guerra de la Independencia, fue comprado en esta ciudad -junto a la alegoría de La Poesía- por el cónsul general de Rusia en Cádiz Alexander Gessler, quien envió sendos lienzos al zar Nicolás I. Éste, mal aconsejado, los rechazó y devolvió a España, desembarcando en Cádiz hacia 1835. Desde allí regresaron a Madrid, donde fueron adquiridos por Juan Duncan Shaw, el excónsul general de Austria. Tras su muerte en 1878, sus descendientes los debieron vender, pues en 1900 se encontraban en la colección madrileña de Luis Navas. En 1916 fueron adquiridos por el norteamericano Charles Deering, de tal modo que La Poesía la destinó a su residencia en Chicago y La Verdad, el Tiempo y la Historia la colgó presidiendo el salón dorado del Palacio Maricelm, mansión que se había hecho levantar en Sitges para albergar sus colecciones de arte. En 1921, cuando abandonó el palacio y se las llevó,

${ }^{33}$ ESTEBAN LORENTE, Juan Francisco, "Jeroglíficos, alegorías y emblemas en Goya", en Artigrama, $n^{\circ}$ 18, 2003, pp. 481-482. ESTEBAN LORENTE, Juan Francisco, "Goya. De la alegoría tradicional a la personal", en Artigrama, n 25, 2010, pp. 103-121.

${ }^{34}$ SAYRE, Eleanor Axson, "Goya. Un momento en el tiempo", en PITA ANDRADE, J.M., ÁlVAREZ LOPERA, J. et al., Goya y la Constitución de 1812, Madrid, Ayuntamiento de Madrid, 1982, pp. 55-69. SAYRE, Eleanor Axson, "La verdad rescatada por el Tiempo ante la Historia como testigo", en Goya y el espíritu de la Ilustración, Madrid: Museo del Prado, 1988, pp. 188-189. ESTEBAN LORENTE, Juan Francisco, "La Constitución Española de 1812 en Goya", en Anales de Historia del Arte, 2008, Volumen Extraordinario, pp. 365-366. GONZÁLEZ TROYANO, Alberto, La reinvención de un cuadro. Goya y "La alegoría de la Constitución de 1812", Madrid, Abada Editores, 2012, passim. 
La Verdad, el Tiempo y la Historia también pasó a Chicago. Después de su fallecimiento en 1927, ambas alegorías fueron compradas por la casa neoyorquina E. y A. Silberman. Finalmente, en 1961 ingresaron en el Museo Nacional de Estocolmo ${ }^{35}$. En consecuencia, Coullaut Valera debió ver y estudiar el lienzo en la colección de Luis Navas. Por aquellos años su denominación era la de El tiempo mostrando a España ante la Historia, al menos con ella fue exhibido en Madrid en la gran exposición que el Ministerio de Instrucción Pública y Bellas Artes dedicó al pintor en mayo de $1900^{36}$. No obstante Coullaut Valera lo interpretó según el título con el que se le venía conociendo a lo largo del siglo XIX y con el que Alexander Gessler se lo presentó al zar Nicolás I, es decir, como El Tiempo y la Verdad escribiendo la Historia ${ }^{37}$. En esta interpretación debió influir el conocimiento de su boceto preparatorio, pintado por Goya entre 1797 y 1799, que llevaba el título de El Tiempo, la Verdad y la Historia, y que también pudo conocer y estudiar directamente, pues por aquellas fechas se encontraba en Madrid, formando parte de la colección de Alejandro de Coupigny, a cuyas manos llegó hacia 1875 después de haber pertenecido a Juan Carnicero, a quien se lo había regalado el mismo Goya. De todas formas, no tardaría mucho en abandonar España, pues en 1918 lo compró Ralph W. Curtis para Horatio Greenough Curtis, de Boston, cuya esposa, tras su muerte, lo donó en 1927 al Museo de Bellas Artes de Boston ${ }^{38}$. En consecuencia, Coullaut Valera interpreta el cuadro como El Tiempo y la Verdad escribiendo la Historia, es decir, desde la perspectiva del título con el que se le conocía en los momentos más cercanos a su realización por Goya, y en base a ella lo toma como punto de partida para la alegoría del reverso de la medalla. Como buen escultor simplificó y clarificó la escena, además de desarrollarla de modo diferente a Goya. Así, en su interpretación alegórica de la Historia quiere mostrarla como una disciplina cuyo objetivo es el conocimiento de los hechos pasados que le muestra el Tiempo, y que lo hace buscando la Verdad. Para

${ }^{35}$ ROSE DE VIEJO, Isadora, "Daños colaterales..., op. cit., págs. 442-443. REYERO, Carlos, Alegoría, Nación..., op. cit., p. 83. BASSEGODA, Buenaventura, DOMENECH, Ignasi, "Charles Deering y el Palacio Maricel de Sitges (Barcelona)", en PÉREZ MULET, Fernando, SOCIAS BATET, Inmaculada (eds.), La dispersión de objetos de arte fuera de España en los siglos XIX y XX, Barcelona, Universitat de Barcelona, 2011, pp. 51-52. "La Verdad, el Tiempo y la Historia", en Fundación Goya en Aragón/ Catálogo, http://www.fundaciongoyaenaragon.es/goya/obra/catalogo/?ficha=165 [03/10/2014 10:25].

${ }^{36}$ Goya 1900: catálogo ilustrado y estudio de la exposición en el Ministerio de Instrucción Pública y Bellas Artes, Madrid, Dirección General de Bellas Artes y Bienes Culturales, Instituto del Patrimonio Histórico Español, 2002, t. II, pp. 91-93.

${ }^{37}$ ROSE DE VIEJO, Isadora, "Daños colaterales..., op. cit., p. 443.

38 "La Verdad, el Tiempo y la Historia (boceto)", en Fundación Goya en Aragón/Catá$\operatorname{logo}$, http://www.fundaciongoyaenaragon.es/goya/obra/catalogo/?ficha=166\&clasificacion $=6 \&$ imagenporpagina $=1 \&$ from $=/$ goya $/$ obra $/$ catalogo $/$ pagina $/ 2 / \&$ clasificacion $=6 \&$ imagen porpagina $=1[03 / 10 / 201410: 30]$. 
ello fusiona en un grupo a la Historia y a la Verdad, y las muestra colaborando juntas en el estudio del pasado que el Tiempo, ante ellas, con su imparable transitar, les va mostrando. De este modo se aparta de la solución goyesca, en tanto que el Tiempo ya no trae a la Verdad para que sea la nueva compañera de la Historia, y también se distancia de Cesare Ripa, quien en su Iconología presentaba a la Historia alada y escribiendo en un libro sobre el hombro del Tiempo, que se convertía así en su inseparable acompañante. Comenzando por la figura de la Historia, la resuelve siguiendo de cerca a Goya, de tal manera que la muestra sentada en una roca, volviendo la cabeza hacia su espalda, escribiendo en el libro que sostiene sobre sus rodillas y semidesnuda, en clara alusión a la verdad como condición de su labor. Para la representación de la Verdad, situada tras ella, se acerca a la Iconología de Ripa, aunque interpretándola con bastantes libertades. Así, no la presenta desnuda sino ligeramente vestida con etéreos ropajes clásicos -chitón e himatión-, próximos a los que luce la Historia, quizá para interconectarlas, y aunque la mantiene en pié, cambia de manos sus atributos, suprimiendo algunos, como la pluma y el libro. De este modo, el Sol, símbolo de la luz, pasa a su mano izquierda convertido en una lucerna con la que ilumina al Tiempo que se acerca a ella y a su compañera, y su mano derecha, exonerada de atributos, se coloca sobre el montón de libros escritos por la Historia con gesto de dar fe de la veracidad de lo allí contenido. Por cierto que la idea para esta pila de libros, que actúa como elemento de enlace formal e iconográfico entre ambas figuras, la toma Coullaut de los textos que pisaba la Historia en el lienzo goyesco. Finalmente, la figura del Tiempo, que completa la escena aproximándose por la izquierda de la composición, es resuelta iconográficamente al modo usual desde el Renacimiento, donde para caracterizarlo se mezclaron atributos propios del Khrónos griego, como la ancianidad, la olímpica desnudez, el aspecto siniestro y el portar una guadaña, con otros referidos al paso del tiempo, como el poseer alas o llevar un reloj de arena. Coullaut, además de dotarlo con todos ellos y sus particulares significados, lo muestra presentándose lenta e inexorablemente ante la Historia y la Verdad con gesto de ofrenda y pleitesía al que éstas responden mirándolo con curiosidad y atención, con lo que se establece una interacción expresiva entre todos los personaje que da cohesión y significado a la alegoría donde la Historia, la Verdad y el Tiempo se integran en un proyecto disciplinar común ${ }^{39}$.

Aunque aparentemente esta medalla sea un encargo adscrito al arte académico y oficial, en realidad fue un homenaje de un grupo de amigos a un eminente intelectual y polígrafo, al que el mismo artista encargado de su realización profesaba gran admiración y afecto. En consecuencia, Coullaut no quiso que su trabajo fuera frío y convencional. Buscó que fuera cercano y emotivo y para ello mira hacia el Modernismo un estilo actual, bello, de moda y apreciado por las

${ }^{39}$ ELVIRA BARBA, Miguel Ángel, Arte y mito: manual de iconografía clásica, Madrid, Sílex, 2013, pp. 52-57. 
élites sociales del momento, y con una fuerte componente emocional y sentimental. Además era un estilo en el que venía trabajado con bastante éxito desde comienzos de siglo, tanto en sus ilustraciones para las revistas Blanco y Negro y La Ilustración Española y Americana como en obras de mayor envergadura, algunas de las cuales le depararon importantes galardones como dos Tercera Medallas y dos Segundas Medallas en las Exposiciones Nacionales de 1901, 1904, 1906 y 1908, respectivamente, por La Anunciación, La Canción de Primavera, Regina Sanctorum Omnium y los modelos del Mausoleo de los Marqueses de Lina$r^{4} s^{40}$. E incluso lo tenía tan vigente, que el monumento a Adolfo Bécquer, encargo de los hermanos Álvarez Quintero para Sevilla, y por aquel entonces en proceso de realización, lo resolvió en esta línea estética. Al respecto cabría recordar que el Modernismo en la escultura madrileña -el ámbito profesional de Coullaut Valera- estuvo muy mediatizado por el realismo académico de los encargos oficiales, de tal modo que siempre fue tímido y tendió más a un simbolismo metafísico, esteticista y sensual donde la mujer era el centro, que a un despliegue decorativo puramente ornamental. No obstante, Coullaut Valera conocía los secretos de este lenguaje, quizá por sus estrechos contactos con el mundo de la ilustración, de modo que en esta medalla pudo dar muestra de los mismos.

Si bien la medalla mantiene el formato tradicional, es decir, el circular, y no se deja llevar por los perímetros cuadrangulares, poligonales, ovoides, florales e irregulares incorporados por el Modernismo, por cuanto busca mostrar el tono sobrio y viril que demanda la personalidad del homenajeado, rompe con otros postulados académicos establecidos para el género. Vemos así como prescinde del cordón y la gráfica, para dejar el campo límpio y de ese modo conseguir un más desembarazado desarrollo del tipo, tanto en el anverso como en el reverso de la medalla. Además, juega libremente con la leyenda y la inscripción, al punto que en el reveso llega a suprimirlas; y las resuelve, no con la tradicional tipografía romana, sino con la más moderna de palo seco, que además trata con una buscada irregularidad en su tamaño y justificación, para así acentuar su apariencia de rotulación manual y como ocurría en el cartelismo Art Nouveau, donde el mismo diseñador hacía la imagen y el texto que la acompañaba, conseguir la perfecta fusión de texto e imagen en un proyecto artístico y comunicativo común. Este recurso, y algunos otros que emplea en ésta obra, los encontró Coullaut en los carteles e ilustraciones modernistas, en especial en los de sus grandes maestros como Henri Toulouse-Lautrec. Si bien ello pudo significar que el tratamiento plástico de la medalla quedara cargado de pictoricismo, Coullaut supo mantener el volumen, la forma, aunque buscó resolverlos desde unos planteamientos nuevos. Estos venían del impacto que la Estampa Japonesa tuvo en el arte del siglo

${ }^{40}$ CASCALES MUÑOZ, José. Las Bellas Artes Plásticas en Sevilla. La pintura, la escultura y la cerámica artística desde el siglo XIII hasta nuestros días, Toledo, 1929, t. II, pp. 68-69. 
XIX, en impresionistas, postimpresionistas y modernistas, que adoptaron el uso de grandes planos de color, la casi ausencia de sombras, el desinterés por la perspectiva, el gusto por las composiciones asimétricas y una clara voluntad de síntesis en el empleo de los recursos pictóricos y en el desarrollo de los asuntos.

El desinterés por la perspectiva y el fingimiento de las tercera dimensión, lleva a Coullaut a situar tanto el retrato de Menéndez y Pelayo como la alegoría de la Historia sobre fondos planos, fundiéndose con ellos sin escorzos o elementos que apelen a la profundidad, con lo que ambos bajorrelieves en su simplificado tratamiento espacial resultan especialmente planos. A esta planitud contribuye la resolución del modelado mediante un nuevo schiacciato que simplifica, achata y ensancha los volúmenes -en correspondencia con los grandes planos de color de las Estampa Japonesa- que parecen responder no tanto a la caracterización mimética del natural como a su propio desarrollo plástico, a una especie de síntesis formal en aras de la belleza, una belleza estilizada, decorativa que apela al propio objeto, a la medalla.

La influencia de estos nuevos planteamientos estéticos derivados del Impresionismo y del Postimpresionismo le lleva a resolver la composición de los tipos de la medalla, y en concreto el del retrato de Menéndez y Pelayo, en base a modelos fotográficos. La comentada fotografía de Kaluraz, no sólo le permite una fidelísima caracterización del polígrafo, sino que le aporta un nuevo modelo de encuadre y composición para su retrato, que se resuelve como un busto prolongado en tres cuartos, en el que se incluyen brazos y manos, apareciendo éstas sobre un pupitre en el que escribe. Además, su figura aparece un poco descentrada, efecto que se ve potenciado por la disposición de la leyenda y la inscripción. También resulta muy interesante la colocación de los libros sobre el referido pupitre, donde estos se representan contemplados simultáneamente desde diferentes puntos de vista, en un claro guiño a las fuentes postimpresionistas que le sirven de guía en esta obra. Muy moderna también resulta la angostura espacial que presentan los dos bajorrelieves que configuran los tipos de la medalla, que parecen comprimirse dentro del marco circular en el que se inscriben. Ésta solución no la emplea Coullaut como recurso expresionista, sino como ocurre en el cartelismo, para que el asunto cobre más visibilidad a los ojos del espectador, y de paso más potencia formal, aspectos ambos que en las medallas, por su poco tamaño, parece obligado reforzar.

Igualmente vinculado al Modernismo y a la estética fin de siglo, y más concretamente a Ramón Casas, quien magistralmente lo había convertido en una solución usual de sus retratos a lápiz, es el tratamiento plástico que Coullaut Valera da al retrato de Menéndez y Pelayo. Como el pintor barcelonés, insiste en los pormenores del rostro, y por extensión la cabeza, para profundizar en la fisonomía y la expresión del personaje, y aboceta el torso con gran economía, logrando la perfecta fusión de figura y fondo, dentro de un concepto moderno, simple y plano. De todas formas, aunque el origen de la solución sea pictórico - Toulouse 
Lautrec y la Estampa Japonesa- Coullaut Valera la resuelve en términos escultóricos: detalla la cabeza con exquisitez, lo que deviene en un logrado claroscuro que potencia la vitalidad del retratado; y resuelve los volúmenes del traje y complementos, extendiéndolos y con una acusada indefinición, con lo que el bajorrelieve se aplana y funden con el fondo.

Por lo que se refiere al bajorrelieve alegórico de la Historia, también se resuelve en la línea modernista que inunda la medalla. La belleza femenina, estilizada, sensual y evanescente de la Historia y la Verdad, parece impregnarlo todo anteponiéndose al contenido iconográfico del asunto. Como en los carteles Art Nouveau, el asunto minimiza el escorzo y se extiende; se resuelve en muy primer término produciendo angostura espacial, que además es acentuada por la adaptación compositiva de las figuras al marco circular; y se ve resaltado en su visibilidad al recortarse sobre un fondo liso que lo potencia. En consonancia con esta buscada bidimensionalidad, y al igual que en la efigie de Menéndez y Pelayo, el modelado se solventa a través de un moderno schiacciato, muy sutil, al punto que parece reflejar la pincelada suelta de Goya, de quien como dijimos toma el modelo iconográfico y hasta cierto punto el compositivo.

En conclusión, esta medalla es un magnifico y elocuente ejemplo de cómo el Modernismo impregnó los primeros años de la carrera escultórica de Lorenzo Coullaut Valera, y de que lo hizo de una manera reflexiva y comprometida con la renovación de la escultura. Su obra modernista no se quedó en recrear damiselas de estilizada y evanescente belleza, rodeadas de exóticos y ondulantes ornamentos, sino que quiso ir más allá, y a tal fin indagó en las posibilidades que para la escultura ofrecían los nuevos recursos lingüísticos planteados por cartelismo y la ilustración gráfica Art Nouveau, cuyo origen estaba en los grandes maestros del Postimpresionismo.

Fecha de recepción: 28 de septiembre de 2014

Fecha de aceptación: 28 de noviembre de 2014 


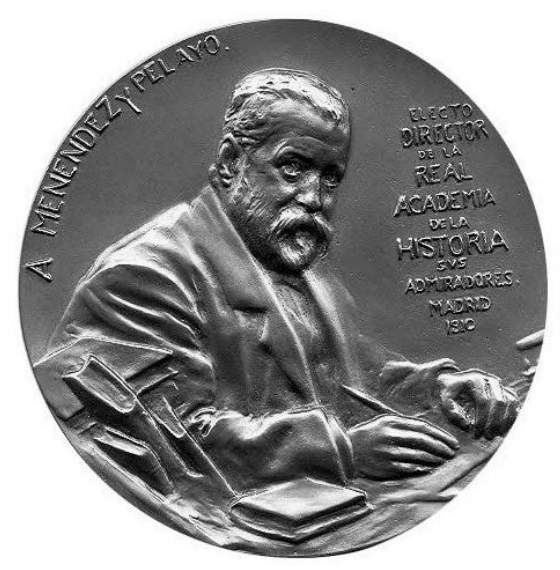

Figura 1. Medalla homenaje a

Marcelino Menéndez y Pelayo por su

elección como director de la Real Academia de la Historia, obra de Lorenzo Coullaut Valera.

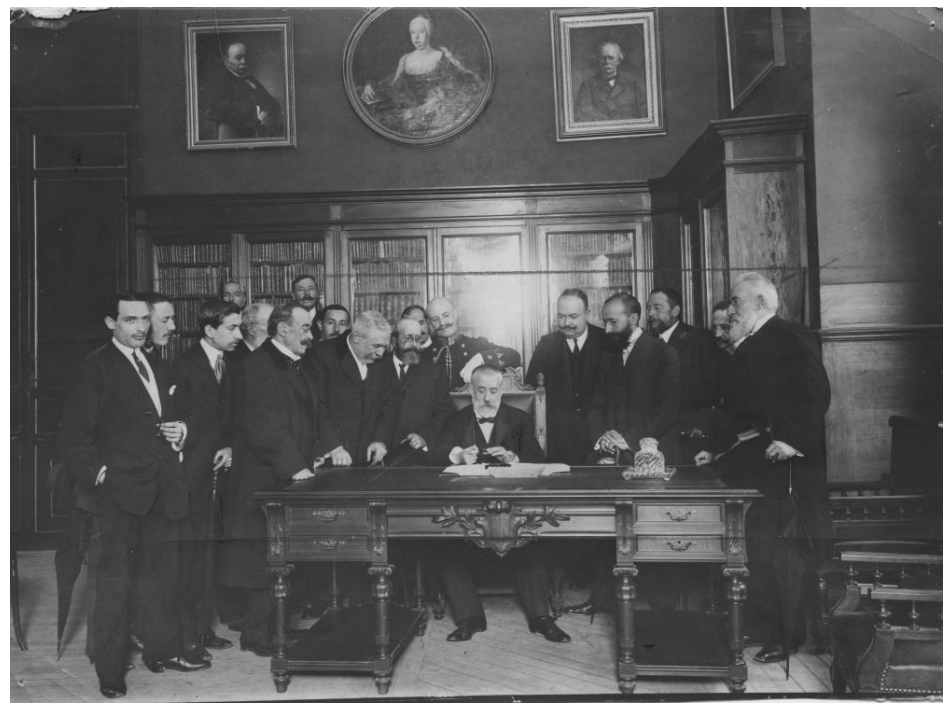

Figura 2. Marcelino Menéndez Pelayo recibiendo el 25 de octubre de 1910, en su despacho de la Biblioteca Nacional, la medalla con la que sus amigos y admiradores le homenajearon por su elección como director de la Real Academia de la Historia. 

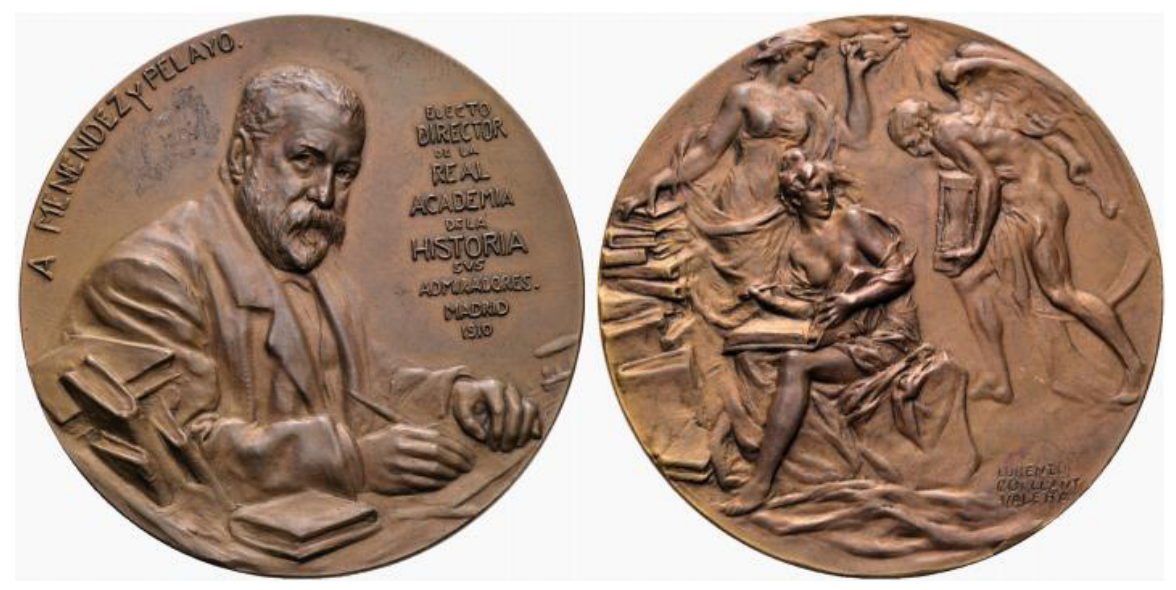

Figura 3. Anverso y reverso de la medalla homenaje a Marcelino Menéndez y Pelayo por su elección como director de la Real Academia de la Historia.

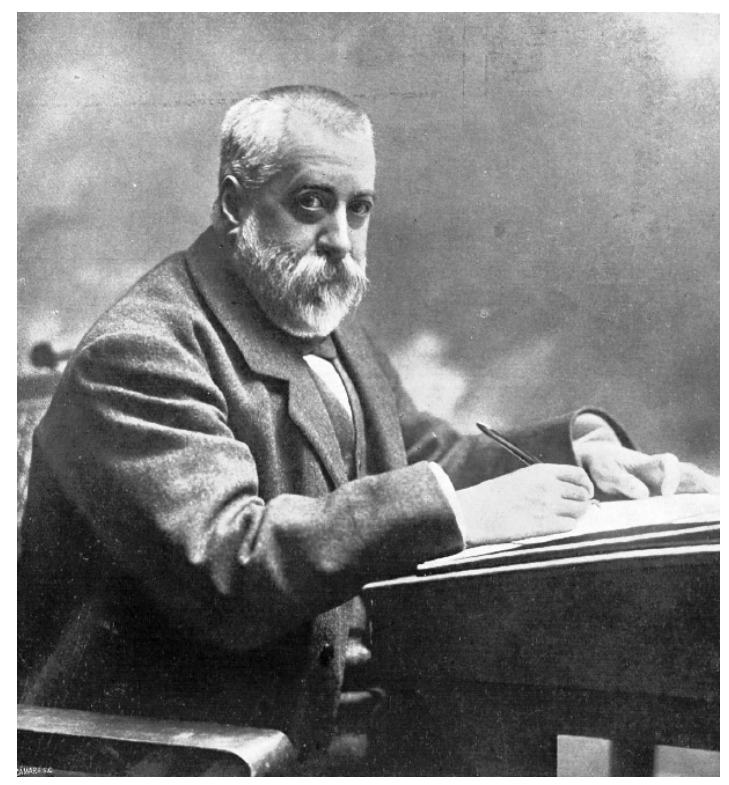

Figura 4. Retrato fotográfico de Marcelino Menéndez y Pelayo obra de Dalton Kaulak, publicado por la revista Mundo Gráfico el 22 de mayo de 1912, pág. 17. 

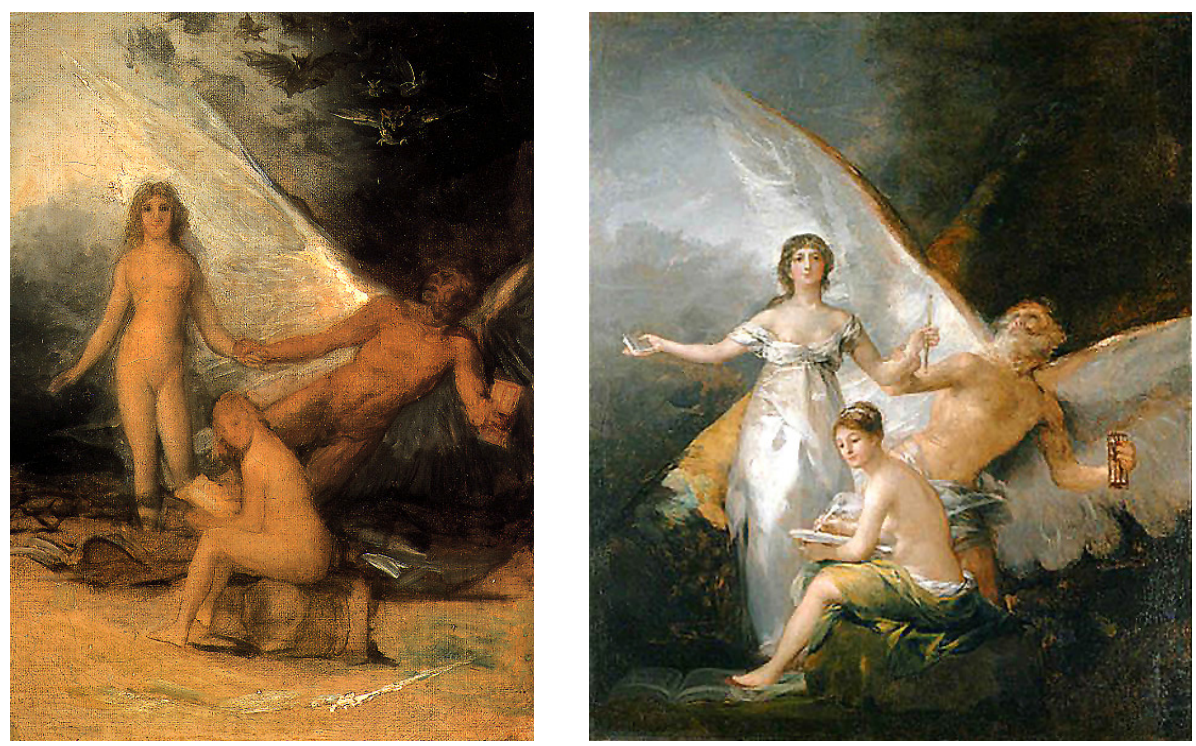

Figura 5. Francisco de Goya: El Tiempo, la Verdad y la Historia, c. 1797-1799, Museo de Bellas Artes de Boston (izq.) y La Verdad, el Tiempo y la Historia, c. 1802-1805, Museo Nacional de Estocolmo (dcha.).
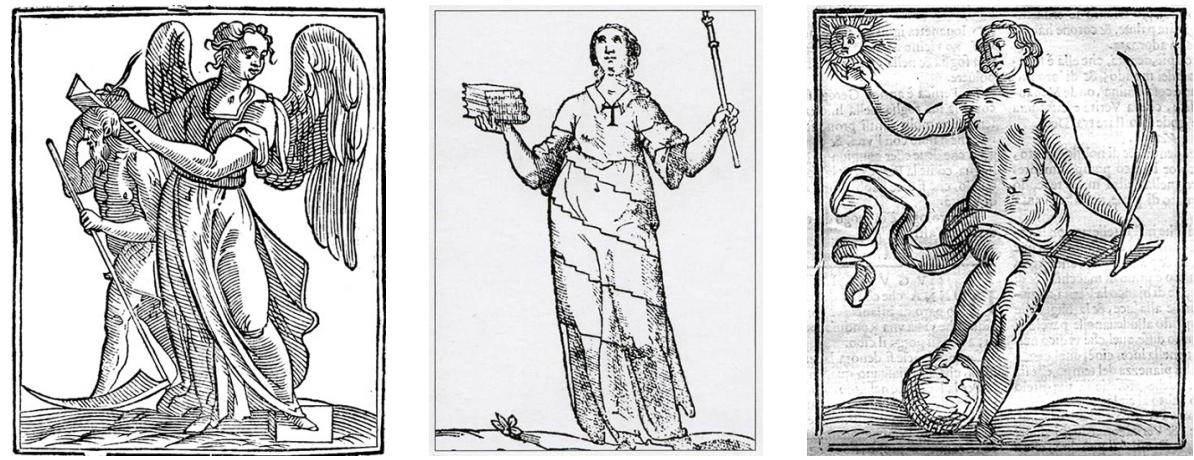

Figura 6. La Historia, la Filosofía y la Verdad, según la Iconología de Cesare Ripa. 